\title{
Mathematics and positive sciences: a reflection following Heidegger
}

\author{
Giorgio T. Bagni
}

Published online: 7 November 2009

(C) Springer Science + Business Media B.V. 2009

\begin{abstract}
In this article, I make a case for the inputs that Martin Heidegger's theoretical perspective offers to current concerns about the nature of mathematics, its teaching and learning, and the problem of subjectivity. In particular, I consider Heidegger's notion of positive science and discuss both its applicability to mathematics and its importance to mathematics education. I argue that Heidegger's ontological position is consonant with some sociocultural approaches in mathematics education and that Heidegger's work can shed some light on the problem of knowing and being. Finally, I raise some questions concerning subjectivity and the link between language and mathematical objects.
\end{abstract}

Keywords Heidegger - Language · Mathematical objects · Philosophy of mathematics · Positive science $\cdot$ Subjectivity

\section{Introduction}

In his monumental work Being and Time (Sein und Zeit), Heidegger introduces an interesting distinction in the way we relate to things. According to Heidegger, we can relate to things as present-at-hand and as ready-to-hand. The term present-at-hand (vorhanden) is used for something that exists. More properly, it is used to describe our attitude toward things in the world as merely "looking at something." In considering an entity as present-athand, one is concerned only with the thing itself. So, a thing revealed as present-at-hand stands apart from its use. In contrast, in ready-to-hand (zuhanden), a thing is revealed to us in the way we use it, with a view toward achieving something. It is hence an entity characterized by the specific use that we make of it. Since our primary experience with entities is as things of use, that is to say as ready-to-hand, presence-at-hand (Vorhandenheit), Heidegger argues, is not the way we encounter things in the world. As Lebedeva (2007, p. 82) notices, for Heidegger the everyday world has a character of

G. T. Bagni passed away on June $10^{\text {th }}, 2009$.

G. T. Bagni $(\bowtie)$

Department of Mathematics and Computer Science, University of Udine, Via delle Scienze 206, 33100

Udine, Italy

e-mail: bagni@dimi.uniud.it 
"equipmental contexture". As a result, the fundamental mode of being in which we disclose entities is readiness-to-hand (Zuhandenheit), which, in Heidegger's account, acquires a foundational ontological state. Indeed, the present-at-hand only emerges from a prior attitude.

This division between the way we relate to abstract and concrete things distinguishes Heidegger's philosophy from other perspectives and has, I will argue, important consequences for our understanding of mathematics and mathematics education. Indeed, most traditional and modern ontologies (e.g., idealist and rationalist ideologies) base their understanding of the relationship between human beings and things in the world on the present-at-hand and hence establish presence-at-hand as the fundamental ontological state. Consequently, our interaction with entities (e.g., geometrical figures, functions, and so on) would not be a primary mode of being (Stepanich, 1991, p. 21), but something that is only derivative. For Heidegger, the manner in which we interact with things is the other way around. In Lebedeva's words (2007, p. 83), "Heidegger points out the somewhat contradictory character of modern ontology by asking: if the being of the thinking subject (res cogitans) is radically different from the being of other things (res extensa), then is it possible to say that there is such a thing as being in general?"

Although Heidegger's philosophical views are difficult to summarize in a brief articlelet alone to trace their development-let me point out that the previous reflections are accompanied in Being and Time by a clear objection to the traditional metaphysical concept of Being. Indeed, Heidegger's programme is not oriented to just shedding some light on the manner in which we relate to things, but also to overcoming the metaphysical concept of Being. The notion of metaphysics is meant by Heidegger in a peculiar way: according to him, metaphysics is the idea that Being is objectively given once and for all, with no possible openness in history and "real" freedom (Vattimo, 2006, p. 1). But how can the overcoming of metaphysics be possible? Later, after his Turn (Kehre), Heidegger's position changed, and the philosopher gave more prominence to the role played by language.

Let me now examine some of Heidegger's ideas about sciences and, more particularly, about mathematics. After such a (short) examination, I shall say something about a hermeneutic approach, taking into account a view of objectification that includes, as a dual process, the question of the creation of subjectivity. I will end my reflections with some considerations about language.

\section{Heidegger, science, mathematics: the science of being and the positive sciences}

Heidegger's thinking on science took into account several perspectives: science as a thought system needing theoretical grounding, science as a practice with an institutional setting, science as a body of knowledge with a historical dimension, etc. (Glazebrook, 2000). Underpinning these ideas is Heidegger's key concept of Dasein - which can be defined as an entity that is conscious of the meaning of its own existence (and this is a fundamental point with regard to human beings).

\subsection{Philosophy and positive sciences}

According to Heidegger, it is possible to consider two kinds of science: the pure science of being, i.e., philosophy, and some different positive sciences:

Science is the founding disclosure, for the sheer sake of disclosure, of a selfcontained region of beings, or of being. . . . It is evident from the idea of science as 
such - insofar as it is understood as a possibility of Dasein - that there are two basic possibilities of science: sciences of beings, of whatever is, or ontic sciences; and the science of being, the ontological science, philosophy. Ontic sciences in each case thematize a given being that in a certain manner is always disclosed prior to scientific disclosure. We call the science of beings as given - of a positum-positive sciences. (Heidegger, 1998, p. 41)

The purpose of Heidegger in this passage that comes from Phenomenology and Theology, written in 1927 and later included in Wegmarken-Pathmarks, is to defend philosophy as a type of science. As such, this passage must be framed with respect to the language game of those early twentieth-century thinkers who considered science as the one and only valid knowledge. However, Heidegger himself took back what he said earlier about considering philosophy a science in his Letter on Humanism (Brief über den Humanismus, 1946-1947; translated in Heidegger, 1977a). Heidegger's conceptual shift has implications for his own conception of mathematics.

\subsection{Science and theory}

In fact, following a Kantian line of thought, Heidegger considered mathematics to be close to physics. In Science and reflection (Wissenschaft und Besinnung, written in 1953; translation included in Heidegger, 1977b), he states that science is the theory of the real. He notices that

the real, in the sense of what is factual, now constitutes the opposite of that which does not stand firm as guaranteed and which is represented as mere appearance or as something that is only believed to be so. . . The real now shows itself as object, that which stands over against. (Heidegger, 1977b, p. 162)

Thus, the modern scientific inquiry disregards what is essential in the authentic knowledge of a thing, that is, the manner in which it presences or becomes knowable. In fact, as Heidegger argued, for the Greeks, the meaning of theory is determined not by what can be measured, as claimed for instance by Max Plank, but as a form of looking attentively upon the aspect of what appears to us. ${ }^{1}$ As Heidegger reminds us,

The word "theory" stems from the Greek verb theörein. The noun belonging to it is theōria ... The verb theōrein grew out of the coalescing of two root words, thea and horao. Thea (cf. theatre) is the outward look, the aspect in which something shows itself, the outward appearance in which it offers itself. Plato names this aspect in which what presences shows what it is, eidos. To have seen this aspect, eidenai, is to know. The second root word in theōrein, horaō, means: to look at something attentively, to look it over, to view it closely. Thus it follows that theorein is thean horan, to look attentively on the outward appearance wherein what presences becomes visible and, through such sight — seeing — to linger with it. (1977b, p. 164)

Hence, the understanding of "theory" conveyed by modern science is in striking opposition to the Greek conception. Heidegger sensed that there was a danger in the attitude of modern science of entrapping and securing the real through calculating procedures. But

\footnotetext{
${ }^{1}$ Heidegger (1997b, p. 169) cites Plank saying that "That is real which can be measured." Heidegger goes on to say that "This means that the decision about what may pass in science, in this case physics, for assured knowledge rests with the measurability, in the possibilities supplied in the objectness of nature and, in keeping with that measurability, in the possibility inherent in the measuring procedure" (p. 169). [Note of the Editor].
} 
what about mathematics? The previous statements are referred essentially to science. Later, in Modern science, metaphysics, and mathematics (Die Frage nach dem Ding, written in 1962; translated in Heidegger, 1978), Heidegger's analysis seems to be more precise for the case of mathematics.

\subsection{The end of philosophy}

However, once again in Modern science, metaphysics, and mathematics, Heidegger treats only cursorily the case of numbers and subsequently proposes long treatments of Aristotelian and Newtonian physics. This position is rather far from the opinion of many present-day mathematicians. In The End of Philosophy (a lecture given during a colloquium on Kierkegaard in Paris, April 21-23, 1964: see Heidegger, 1973), we find the disillusionment with philosophy and science accompanied by the final deconstruction of Western metaphysics. ${ }^{2}$ The development of sciences has a major role in this phase:

Already in the age of Greek philosophy a decisive characteristic of philosophy appears: the development of sciences within the field which philosophy opened up. The development of the sciences is at the same time their separation from philosophy and the establishment of their independence. This process belongs to the completion of philosophy. Its development is in full swing today in all regions of beings. This development looks like the mere dissolution of philosophy, and in truth is precisely its completion. (Heidegger, 1973, I-7)

\subsection{Is mathematics an ontic science?}

So Heidegger's ideas about sciences and mathematics changed remarkably in the development of his life. Heidegger's previously quoted claim about positum (1998, p. 41) is interesting, especially if compared with the opposition between present-at-hand and ready-to-hand previously sketched.

Let me turn back to positive sciences. The term "positive" refers to a positum, a given being that is partially known in the pre-scientific stage, with reference to a particular science. In Heidegger's perspective, what is scientifically knowable is given in advance by a "truth" which is not graspable by positive sciences. Beings constitute the positum of the science, so every particular science is a "positive" science in itself.

Heidegger's distinction of philosophy as ontological science from all other ontic sciences is important for the purpose of affirming that the starting point of any scientific reflection is always a pre-given awareness of being. This would be a trivial statement. A question in response could be: should we regard mathematics as a positive (ontic) science?

Any answer to this inquiry would be questionable and open to doubt. It would be influenced by several viewpoints and (counter) examples. Of course, Heidegger's idea of mathematics as an ontic science could hardly include non-Euclidean geometries and Hilbert's formalist programme (see Kline, 1980). Nevertheless, mathematics is not properly a philosophy, and, generally, doing mathematics does not strictly require ontological reflection. According to Heidegger, philosophy is mainly an activity of ontological

\footnotetext{
${ }^{2}$ Since the openness of being refers to situations within history, one of the most important conceptions of later Heidegger is the historical dimension of being. It is worth noting that the declaration of the end of philosophy started with Hegel, and has been reprised in the twentieth century by Carnap, Wittgenstein, and Rorty. See Bagni (2008).
} 
questioning, so philosophers and scientists "philosophize" if they seek to clarify the ontological understanding that guides a science implicitly (Glazebrook, 2000). An interesting point stated by Heidegger in his Phenomenology and Theology (1927) is that "theology, as a positive science, is in principle closer to chemistry and mathematics than to philosophy" (Heidegger, 1998, p. 41).

However, these remarks do not amount to claiming that number, space, time, motion, lines, and figures must be somehow known before any systematic analysis - several theoretical frameworks could be considered for a critical comparison, like the one suggested by Lakoff \& Núñez (2000). The point is: does that mean that they are "positive beings" in the same sense as physical objects? More precisely, how could we describe some given beings, partially known in the pre-scientific stage, about which mathematicians work? This issue is important with reference to mathematics education, insofar as the role of this positum (and of its historico-cultural background) can be relevant to our educational choices (Radford, 2003).

I shall try to tackle the aforementioned questions in the next section, making reference to Heidegger's distinction between present-at-hand and ready-to-hand. Now, I briefly discuss the existence and the role of the positum of mathematics.

As a first possibility, we could make reference to mathematical experiences, historically and culturally framed. By "mathematical experiences" we mean any activity whose objects, methods, and goals have been framed into a theoretical thought system called "mathematics" in various historical and cultural contexts. Nevertheless, a problematic issue must be taken into account: in this case, mathematics itself, generally considered, would be a part of mentioned experiences, with a progressive historical and cultural articulation. As a matter of fact, mathematics can hardly be considered apart from its history, and every historical discipline is an historical phenomenon, a sort of self-awareness of the history itself, of course with a specific historical dimension (Heidegger, 1998). It follows that the statement according to which mathematics is the self-awareness of different mathematical experiences cannot be considered a completely correct position: in fact, every mathematical experience is connected with a general cultural reality, in different historical periods.

As a consequence, we should refer to a more complex model. In particular, we should take into account a hermeneutic reprise of mathematical experiences in order to build up some conceptual knowledge. In this approach, mathematics can be considered the conceptual interpretation of mathematical experiences, articulated, for instance, into a three-folded model (consisting namely of systematic, historical and practical dimensions). Thus, if we consider mathematics as a positive science, its positum is not only a set of experiences determining mathematics itself. Its positum, rather, is something that needs a hermeneutic activity.

The formal description of the pre-scientific contents of mathematical concepts is a philosophical issue (Heidegger, 1998). It is worth noting that, if correctly proposed, their description will not be performed only through the definition of some isolated concepts. Rather, it must be performed by taking into account the primary connection of all fundamental concepts in the pure science of Being (as stated in Heidegger, 1998). This is not our goal. Nevertheless, the remark that doing mathematics requires a hermeneutic activity over mathematical experiences (hence the necessary reflective thinking about experience) can be reprised taking into account some of Heidegger's ideas previously sketched.

\section{Mathematics: present-at-hand or ready-to-hand?}

The above considerations do not offer an encompassing view of the relationship between mathematics and the individuals who practice and learn it. This relationship can be explored 
further in two different ways. First, by taking into account the opposition between presentat-hand and ready-to-hand (following the distinction introduced by Heidegger in Being and Time and previously sketched in section 1). Second, by considering the role of language (following the "second" Heidegger, after his Turn). In this section, I explore both avenues and suggest some links to current discussions in mathematics education.

\subsection{Mathematics and readiness-to-hand}

As previously mentioned, in Heidegger's account of our relationship to things in the world, two different attitudes need to be distinguished: readiness-to-hand and presence-at-hand. While the former entails a foundational ontological state, the latter constitutes a secondary state that emerges from the prior attitude. To state that presence-at-hand is only a secondary state amounts to emphasizing the role of human beings (Dasein) vis-à-vis the world. Indeed, according to Heidegger, human beings are not only observers of the world, referred to a form of theoretical consciousness (as in Kant): human beings are instead involved in the world. This fundamental aspect needs a further inquiry.

Let us consider what Heidegger calls the ontological difference, i.e., the difference between entities and the being of entities. It is clear that the existence of a mountain, a river, or a fork that I find on a table is independent of my own existence. Yet, the being of these entities is not. As Stepanich notes (Stepanich, 1991, p. 20), having established this difference between entities and the being of entities, "Heidegger claims that, although natural objects are independently of human beings, the being of these objects is only in human understanding".

According to Heidegger, "entities are, quite independently of the experience by which they are disclosed, the acquaintance in which they are discovered, and the grasping in which their nature is ascertained" (1962, p. 228). These entities are uncovered and made intelligible to us, but they are both prior to and apart from our encounter with them. Nevertheless, Heidegger's realism is limited: "Being is only in the understanding of those entities to whose Being something like an understanding of Being belongs" (Heidegger, 1962, p. 228).

This entity is Dasein (as mentioned in Section 1, this is Heidegger's term to designate human beings, considered both individually and collectively, and their specific manner of being). Human beings (Dasein) are unique among entities in that they are concerned about their existence (Stepanich, 1991). So Heidegger claims that entities of the world other than human beings (Dasein) do not properly exist. Based on this concern for its being, Dasein is in the unique position "that with and through its Being, this Being is disclosed to it. Understanding of Being is itself a definite characteristic of Dasein's Being" (Heidegger, 1962, p. 32, emphasis as in the original).

It is very important to notice that human beings (Dasein) cannot be without the world, and the world itself cannot be without human beings. As a consequence, Dasein's Being is necessarily Being-in-the-world (In-der-Welt-Sein): the being of Dasein and the world are not separate entities but must be grasped together. In this sense, there is no subject and object. So Heidegger rejects Descartes' dualism, i.e., the distinction between subject and object, by arguing that there is no subject distinct from the external world because Dasein is essentially Being-in-the-world. This, of course, is a crucial point. It provides us with a new way in which to envision the relationship between knowledge, world, and beings.

\subsection{Mathematics and the hermeneutic approach}

Objectivity has been a chief concern of sciences in the naturalistic tradition. In such a tradition, subjectivity has been simply erased. Indeed, subjectivity has been seen as the 
opposite of objectivity. Now, according to Edmund Husserl (who was Heidegger's master) the notion of objectivity cannot be seen as the antithesis of subjectivity. Husserl stated:

The naivete of talk about "objectivity" which completely ignores experiencing, knowing subjectivity, subjectivity which performs real concrete achievements, the naivete of the scientist concerned with nature, with the world in general, who is blind to the fact that all truths that he acquires as objective, and the objective world itself that is the substratum in his formulation, is his own life construct that has grown within him, is of course, no longer possible when life comes on the scene. (Husserl, 1993, quoted in Gadamer, 1989, p. 220)

In his recent book, $\mathrm{T}$. Brown argues that interpretation might assume a more central role in mathematical understanding. He says: "By shifting the emphasis from what a statement might mean to how it has been used by someone in a specific situation, the human agent becomes implicated, and a certain perspective gets revealed" (2001, p. 24). The following passage shows several connections with Heidegger's position:

Hermeneutics . . . is governed by a belief that whilst the world may exist independently of humans, it cannot present itself directly to human gaze. It attends to the process through which we develop an understanding of the world. The hermeneutic task can be seen as an uncovering of meaning, but a historically situated meaning dependent on the media and experiences through which it is observed. Further, we can never uncover a meaning free of the conditions that gave rise to us and of the particular perspective we assume. (Brown, 2001, p. 24)

In the first part of this section, I discussed some aspects of the theoretical system of Being and Time that can be related to a form of (limited) realism (see Heidegger, 1962, p. 251). Does Heidegger's nuanced realism apply to mathematics? According to Realists, mathematical objects exist and their existence precedes and is independent from the activity of individuals, as well as from historical and cultural context. This position cannot be framed into Heidegger's philosophy, which is much closer to the hermeneutic position expressed by Brown, according to whom "by seeing mathematical expressions as being used by humans in particular situations, rather than as things with inherent meaning, emphasis is placed on seeing mathematical activity as a subset of social activity" (Brown, 2001, p. 25).

This perspective leads us to make reference to modern sociocultural approaches, according to which knowledge is historically generated during the course of the mathematical activity of individuals (Radford, 2008a, b).

\subsection{Being-in-the-world}

Dasein's Being, we already noted, is necessarily Being-in-the-world, and in this sense, there is no subject and object. This is close to the theoretical views underpinning Radford's approach to learning. As he suggests, "learning rests on an attitude of open-mindedness: it is an opening movement towards others and the objects of culture" (Radford, 2008a, p. 225). It is worth noticing in this respect that in Heidegger's philosophy the openness, Erschlossenheit, is a fundamental character of the Dasein that intentionally opens itself to the world before all knowledge — a move through which Heidegger rejects and breaks with the traditional theory of knowledge based on the Cartesian distinction between subject and object (see Heidegger, 1988, p. 176; Çüçen, 1998). Since "knowing has the phenomenal character of a Being which is in and towards the world" (Heidegger, 1962, p. 87), knowing 
is grounded beforehand in a Being-already-alongside-the-world. But this groundness cannot be considered as something present-at-hand because, for "Being-in-the-world, as concern, is fascinated by the world with which it is concerned" (Heidegger, 1962, p. 88). Certainly, there is a definite and important influence of the world upon human beings. As Lebedeva (2007, p. 82) notes, "Dasein returns to itself from out of things, equipment, tools". But this is not all: "Dasein can also come back to itself from other Dasein" (2007, p. 82), that is to say from other human beings through social interaction.

These two sources of Dasein are chief distinguishing features of contemporary sociocultural approaches. As Radford (2008a) argues, such approaches put forward two important sources of meanings that underlie all forms of learning: knowledge deposited in artifacts (tools, signs, objects, etc.) and knowledge that arises from social interaction. But these are more than sources of knowledge. They are also sources of the self:

sociocultural approaches resist ... the idea that learning is just the uncritical appropriation of existing knowledge absorbed by a passive student-spectator. Knowledge has a transformative power: it transforms the object of knowledge and, in the course of knowing and learning, the subject is itself transformed. There is a dialectical relationship between subject and object that can be better understood by saying that learning is a process of objectification (knowing) and subjectification (or agency), that is a process of being. (Radford, 2008b, p. 12)

This is why, for sociocultural approaches, the act of learning cannot be summarized in the construction of concepts. Objectification (as considered in Radford, 2002) is more than the connection between the poles of subject and object: it is in fact

a transformative and creative process between these two poles, where, in the course of learning, the subject objectifies cultural knowledge and, in so doing, finds itself objectified in a reflective move that can be termed subjectification. The making of the subject, the creation of a particular (and unique) subjectivity is thus a process of subjectification that is made possible by the activity in which objectification takes place. (Radford, 2008a, p. 225)

It is clear that these ideas resonate with Heidegger's concept of Being-in-the-world. Our mode of existence is not just a theorization of the world in front of us, which would be present-at-hand. In this view, mathematics is not merely a body of knowledge. Indeed,

mathematics is much more than just a form of knowledge production-an exercise in theorization. If it is true that individuals create mathematics, it is no less true that, in turn, mathematics affects the way individuals are, live and think about themselves and others. (Radford \& Empey, 2007, p. 250)

These remarks lead us to reflect on the ethical and political dimension of mathematics and its objects. Mathematical objects were forged by mathematicians in the course of history, while pedagogical actions in contemporary classrooms are directed at making them available to our students. We should not forget that mathematical objects affected-and, nowadays, affect - "all of society and not only those who practice it in a professional way" (Radford \& Empey, 2007, p. 251).

It seems to me that the dual aspects of objectification and subjectification are consonant with Heidegger's idea of Dasein and must be clearly pointed out in educational processes, in order to allow for the students' full and conscious growth. This could lead us to consider Heidegger's important notions of authenticity (Eigentlichkeit) and inauthenticity. As Heidegger claimed in an important lecture course he gave in the summer of 1927, our 
everyday self-understanding is not authentic insofar as it does not arise from "the most proper and most extreme possibilities of our own existence" (Heidegger, 1988, p. 160).

Let us now turn back to an essential aspect of the "second" Heidegger: the major role of language.

\section{Mathematical objects and language}

Is language only an instrument that we employ to manipulate objects? Is language at all within the human being's power of disposal? . . . Is the human being that being that has language in its possession? Or is it language that "has" human beings, insofar as they belong to, pay heed to language, which first open up the world to them and at the same time thereby their dwelling in the world?

Martin Heidegger (1998, p. 59)

The problem of the connection between the formation of mathematical objects and their expressions in mathematical languages deserves a careful discussion. Equally important is the problem of the relationship between thinking and speaking. Of course, these two problems are related. For Heidegger, "thinking and speaking belong together, [they] form

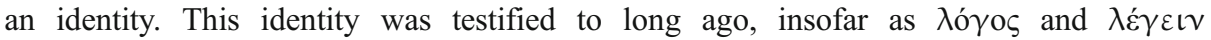
simultaneously signified talking and thinking" (Heidegger, 1998, p. 59). Heidegger holds a hermeneutic position that is at odds with the technical conception of language (like Carnap's). According to him (see the Appendix to Phenomenology and Theology, a short paper written in 1964: Heidegger, 1998, pp. 54-62), languages cannot be considered merely sets of signs or sounds introduced in order to describe procedures (to be objectified). In fact, often in mathematics education we use the term object, but it is difficult to find a clear and shared notion of it (Slavit, 1997). In a Kantian perspective, for instance, an object is assumed to exist and to be directly considered (Gegenstand), as in the experience of natural sciences. Now, in Phenomenology and Theology (written in 1927), Heidegger (1998) claims that our experience, generally speaking, cannot be identified with objectification or reification. Heidegger states that when we think we do not necessarily represent something as an object.

These considerations about language support our previous reflections about objectification and subjectification as dual parts of each other (Radford, 2008a). An important question to be considered is: do mathematics and its didactics need a language which (only) allows the formation of objects? My answer is no. From a cognitive viewpoint, the problem is not to show how a process becomes an object. Such a view reduces the world (material and conceptual) to a view of processes as "things." The problem is rather to understand how the students, through social semiotic processes, make sense of the cultural and mathematical logic behind considered processes. These processes are not about converting something into an object, but about becoming progressively "aware" of the way signs become meaningfully understood and creatively employed by the students (Radford, 2008a).

Slavit (1997, p. 265) notices a "lack of clarity" when an object-oriented comprehension of a mathematical ideas is stated. This might be one of the reasons why several theoretical frameworks (Sfard, 1999; Radford, 2003, 2008a) recently evolved and abandoned a strictly hierarchic and sequential approach (from procedures to objects). Connections between processes and objects granted importance to dialectic dimensions of various steps and to semiotic aspects of conceptualization activities. 


\section{Concluding remark}

In this paper, I attempted to call attention to the potential contribution of some aspects of Heidegger's philosophy to the challenges that we face as mathematics educators. I tried to make a case for the inputs that Heidegger offers in particular to current concerns about the nature of mathematics, its teaching and learning, and the problem of subjectivity. For one thing, Heidegger offers an interesting non-dualistic way of theorizing that has challenged the Cartesian legacy in epistemology (Heidegger, 1988). It is worth noticing that the modern tendency towards individualism started with Descartes' statement of the major role of the cogito (Çüçen, 1998). Moreover, the modern technological orientation similarly originated in the Cartesian understanding of the mathematical-physical character of the world (Guignon, 1983). Heidegger's philosophical work is a challenge to both individualism and instrumentalism. I hope that these aspects of Heidegger's philosophy contribute to current discussions in our field - particularly to discussions about subjectivity and agency (e.g., Bagni, 2006; Brown, 2008; Presmeg \& Radford, 2008; Radford, Schubring, \& Seeger, 2008).

Of course the aim of my reflections was neither to develop these ideas nor to give complete answers to these questions. I wanted to explore some hints by a great philosopher and to suggest a field of reflection for mathematics educators. Further research will be devoted to analyzing real classroom episodes in order to (try to) provide experimental evidence to previous suggestions. As H.-G. Gadamer famously concluded the "Afterword" to his masterpiece, Truth and Method, "the ongoing dialogue permits no final conclusion. It would be a poor hermeneuticist who thought he could have, or had to have, the last word" (Gadamer, 1989, p. 579).

\section{References}

Bagni, G. T. (2006). Some cognitive difficulties related to the representations of two major concepts of set theory. Educational Studies in Mathematics, 62(3), 259-280. doi:10.1007/s10649-006-8545-3.

Bagni, G. T. (2008). Richard Rorty (1931-2007) and his legacy for mathematics educators. Educational Studies in Mathematics, 67(1), 1-2. doi:10.1007/s10649-007-9096-y.

Brown, T. (2001). Mathematics education and language. Interpreting hermeneutics and post-structuralism. Dordrecht: Kluwer.

Brown, T. (2008). Lacan, subjectivity, and the task of mathematics education research. Educational Studies in Mathematics, 69(3), 249-263. doi:10.1007/s10649-007-9111-3.

Çüçen, A. K. (1998). Heidegger's reading of Descartes' dualism: The relation of subject and object. Proceedings of the twentieth World Congress of Philosophy (WCP-20), Boston, Massachusetts, USA, 10-15 August 1998. Retrieved from http://web.bu.edu/wcp/Papers/Cont/ContCuce.htm

Gadamer, H. G. (1989). In J. Weinsheimer \& D. G. Marshall (Eds.), Truth and method. New York: Crossroads. Original work published 1960.

Glazebrook, T. (2000). Heidegger's philosophy of science. New York: Fordham University Press.

Guignon, C. B. (1983). Heidegger and the problem of knowledge. Indianapolis: Hackett.

Heidegger, M. (1962). In J. Macquarrie, \& E. Robinson (Eds.), Being and time. Oxford: Blackwell, (Original work published 1927).

Heidegger, M. (1973). In J. Stambaugh (Ed.), The end of philosophy. Harper \& Row: New York. (Original work published 1969).

Heidegger, M. (1977a). Letter on humanism. In D. F. Krell (Ed.), Basic writings (pp. 217-265). London: Routledge \& Kegan Paul. Original work published 1947.

Heidegger, M. (1977b). Science and reflection. In W. Lovitt (Ed.), The question concerning technology and other essays (pp. 155-182). New York: Harper \& Row. Original work published 1994.

Heidegger, M. (1978). Modern science, metaphysics, and mathematics. In D. F. Krell (Ed.), Basic writings (pp. 247-282). London: Routledge \& Kegan Paul. Original work published 1962. 
Heidegger, M. (1988). The basic problems of phenomenology (Albert Hofstadter, Trans.). Bloomington: Indiana University Press. Original work published 1992.

Heidegger, M. (1998). In W. A. McNeill (Ed.), Pathmarks. Cambridge: Cambridge University Press. Original work published 1976.

Husserl, E. (1993). Die Krisis der europäischen Wissenschaften und die transzendentale Phänomenologie: Eine Einleitung in die phänomenologische Philosophie [The crisis of European sciences and transcendental phenomenology: An introduction to phenomenological philosophy]. Dordrecht: Kluwer.

Kline, M. (1980). Mathematics: The loss of certainty. New York: Oxford University Press.

Lakoff, G., \& Núñez, R. (2000). Where mathematics come from? How the embodied mind brings mathematics into being. New York: Basic Books.

Lebedeva, K. (2007). The role of Techne in the Authenticity-Inauthenticity Distinction. Kritike, 1(2), 82-96. Retrieved from http://www.kritike.org/journal/issue_2/lebedeva_december2007.pdf.

Presmeg, N., \& Radford, L. (2008). On semiotics and subjectivity: a response to Tony Brown's "signifying 'students', 'teachers', and 'mathematics': a reading of a special issue". Educational Studies in Mathematics, 69(3), 265-276. doi:10.1007/s10649-008-9146-0.

Radford, L. (2002). The seen, the spoken and the written. A semiotic approach to the problem of objectification of mathematical knowledge. For the learning of mathematics, 22(2), 14-23.

Radford, L. (2003). On the epistemological limits of language: mathematical knowledge and social practices during the Renaissance. Educational Studies in Mathematics, 52(2), 123-150. doi:10.1023/ A: 1024029808871.

Radford, L. (2008a). The ethics of being and knowing: towards a cultural theory of learning. In L. Radford, G. Schubring \& F. Seeger (Eds.), Semiotics in Mathematics Education: Epistemology, History, Classroom, and Culture (pp. 215-234). Rotterdam: Sense Publishers.

Radford, L. (2008b). Theories in mathematics education: A brief inquiry into their conceptual differences. Working Paper prepared for the ICMI Survey Team 7. Retrieved from http://www.laurentian.ca/NR/ rdonlyres/77731A60-1A3E-4168-9D3E-F65ADBF37BAD/0/radfordicmist7.pdf

Radford, L., \& Empey, H. (2007). Culture, knowledge and the self: Mathematics and the formation of new social sensibilities in the Renaissance and Medieval Islam. Revista Brasileira de História da Matemática. Festschrift U. D’Ambrosio, 231-254.

Radford, L., Schubring, G., \& Seeger, F. (eds). (2008). Semiotics in mathematics education. Epistemology, History, Classroom, and Culture. Rotterdam: Sense Publishers.

Sfard, A. (1999). Symbolizing mathematical reality into being: how mathematical discourse and mathematical objects create each other. In P. Cobb, E. Yackel \& K. McClain (Eds.), Symbolizing and communicating: perspectives on mathematical discourse, tools, and instructional design (pp. 37-98). Mahwah: Erlbaum.

Slavit, D. (1997). An alternate route to reification of function. Educational Studies in Mathematics, 33(3), 259-281.

Stepanich, L. V. (1991). Heidegger: Between idealism and realism. Harvard Review of Philosophy, 1, 20-29.

Vattimo, G. (2006). The end of philosophy in the age of democracy. Le Portique, 18, Heidegger. La pensée à l'heure de la mondialisation. Retrieved from http://leportique.revues.org/document811.html 